\title{
Serum alkaline phosphatase levels and the risk of new-onset diabetes in hypertensive adults
}

\author{
Yuanyuan Zhang ${ }^{1}$, Chun Zhou' ${ }^{1}$, Jianping Li ${ }^{2}$, Yan Zhang ${ }^{2}$, Di Xie ${ }^{1}$, Min Liang ${ }^{1}$, Binyan Wang ${ }^{3}$, Yun Song ${ }^{4}$,
} Xiaobin Wang ${ }^{5}$, Yong Huo ${ }^{2}$, Fan Fan $\mathrm{Hou}^{1}$, Xiping $\mathrm{Xu}^{1^{*}}$ and Xianhui Qin ${ }^{1 *}(\mathbb{D}$

\begin{abstract}
Background: The association between alkaline phosphatase (ALP) and incident diabetes remains uncertain. Our study aimed to investigate the prospective relation of serum ALP with the risk of new-onset diabetes, and explore possible effect modifiers, in hypertensive adults.

Methods: A total 14,393 hypertensive patients with available ALP measurements and without diabetes and liver disease at baseline were included from the China Stroke Primary Prevention Trial (CSPPT). The primary outcome was new-onset diabetes, defined as physician-diagnosed diabetes or use of glucose-lowering drugs during follow-up, or fasting glucose $\geq 7.0 \mathrm{mmol} / \mathrm{L}$ at the exit visit. The secondary study outcome was new-onset impaired fasting glucose (IFG), defined as $F G<6.1 \mathrm{mmol} / \mathrm{L}$ at baseline and $\geq 6.1$ but $<7.0 \mathrm{mmol} / \mathrm{L}$ at the exit visit.

Results: Over a median of 4.5 years follow-up, 1549 (10.8\%) participants developed diabetes. Overall, there was a positive relation of serum ALP and the risk of new-onset diabetes (per SD increment, adjusted OR, 1.07; 95\% Cl: $1.01,1.14$ ) and new-onset IFG (per SD increment, adjusted OR, 1.07; 95\% Cl: 1.02, 1.14). Moreover, a stronger positive association between baseline ALP (per SD increment) with new-onset diabetes was found in participants with total homocysteine (tHcy) $<10 \mu \mathrm{mol} / \mathrm{L}$ (adjusted OR, 1.24; 95\% Cl: 1.10, 1.40 vs. $\geq 10 \mu \mathrm{mol} / \mathrm{L}$ : adjusted OR, 1.03; 95\% Cl: 0.96, 1.10; $P$-interaction $=0.007$ ) or $F G \geq 5.9 \mathrm{mmol} / \mathrm{L}$ (adjusted $\mathrm{OR}, 1.16 ; 95 \% \mathrm{Cl}: 1.07,1.27 \mathrm{vs} .<5.9 \mathrm{mmol} / \mathrm{L}$ : adjusted OR, $1.00 ; 95 \% \mathrm{Cl}: 0.93,1.08 ;$ P-interaction $=0.009)$
\end{abstract}

Conclusions: In this non-diabetic, hypertensive population, higher serum ALP was significantly associated with the increased risk of new-onset diabetes, especially in those with lower HHcy or higher FG levels.

Clinical Trial Registration-URL Trial registration: NCT00794885 (clinicaltrials.gov). Retrospectively registered November 20, 2008.

Keywords: Alkaline phosphatase, New-onset diabetes, New-onset impaired fasting glucose, Total homocysteine, Hypertension

\footnotetext{
*Correspondence: xipingxu126@126.com; pharmaqin@126.com ${ }^{1}$ Division of Nephrology, Nanfang Hospital, Southern Medical UniversityNational Clinical Research Center for Kidney DiseaseState Key Laboratory of Organ Failure ResearchGuangdong Provincial Institute of Nephrology, Guangdong Provincial Key Laboratory of Renal Failure Research, Guangzhou Regenerative Medicine and Health Guangdong Laboratory, Guangzhou 510515, China

Full list of author information is available at the end of the article
}

\section{Background}

Diabetes mellitus has been a public issue with increasing prevalence worldwide $[1,2]$. The global diabetes prevalence in 2019 is estimated to be $9.3 \%$ (463 million people), projected to reach $10.2 \%$ (578 million) by 2030 and $10.9 \%$ (700 million) by 2045 [1]. Diabetes result in many complications, including cardiovascular disease (CVD)

c) The Author(s) 2020. This article is licensed under a Creative Commons Attribution 4.0 International License, which permits use, sharing, adaptation, distribution and reproduction in any medium or format, as long as you give appropriate credit to the original author(s) and the source, provide a link to the Creative Commons licence, and indicate if changes were made. The images or other third party material in this article are included in the article's Creative Commons licence, unless indicated otherwise in a credit line to the material. If material is not included in the article's Creative Commons licence and your intended use is not permitted by statutory regulation or exceeds the permitted use, you will need to obtain permission directly from the copyright holder. To view a copy of this licence, visit http://creativeco mmons.org/licenses/by/4.0/. The Creative Commons Public Domain Dedication waiver (http://creativecommons.org/publicdomain/ zero/1.0/) applies to the data made available in this article, unless otherwise stated in a credit line to the data. 
and chronic kidney diseases (CKD), amputation and vision problems $[3,4]$. The identification of more modifiable risk factors may possibly reduce the huge burden of diabetes and its associated complications by leading to early detection and prevention.

Prior studies have reported that liver function may be associated with diabetes $[5,6]$. Alkaline phosphatase (ALP) is a generally accepted clinical marker of hepatic or bone disease [7]. It had been showed that elevated ALP acted as a prognostic indicator of decreased survival in diabetic patients with acute myocardial infarction (MI), possibly in association to decreased renal function in male patients [8]. At the same time, the combined effect of vascular calcification (VC) and higher ALP was associated with a greater risk of cardiovascular events and death, and high serum ALP increased the risk associated with $\mathrm{VC}$ in end-stage kidney disease patients starting dialysis [9]. Moreover, in a nest case-control study, ALP in type 2 diabetes seemed to be associated with CVD risk and stroke incidence in men, but with borderline significance [10]. However, only a few previous prospective studies [11-14] have been carried out to evaluate the relation of ALP and incident diabetes, and reported inconsistent results. In addition, although hypertension is one of the important risk factors for diabetes $[3,15,16]$, few related studies has been conducted in hypertensive patients. More importantly, potential modifiers on the association between ALP and incident diabetes have not been comprehensively examined in previous studies.

This study was motivated by the limited and inconclusive evidence regarding the ALP levels and incident diabetes, and a special opportunity to address this question in a large, randomized controlled trial with regular antihypertensive treatments, BP measurements and diabetes status reports. Specifically, using data from China Stroke Primary Prevention Trial (CSPPT) [17], we aimed to investigate the prospective association between serum ALP and new-onset diabetes among hypertensive adults, and to examine possible modifiers on the association.

\section{Methods}

\section{Study design and participants}

The study design, methods and major results of the CSPPT (ClinicalTrials.gov identifier NCT00794885) have been reported elsewhere in detail [17-22]. Briefly, the CSPPT was a multi-community, randomized, double-blind, controlled trial conducted from May 19, 2008 to August 24, 2013 in 32 communities in Anhui and Jiangsu provinces in China. Eligible participants were men and women aged 45-75 years who had hypertension, defined as seated, resting systolic blood pressure $(\mathrm{SBP}) \geq 140 \mathrm{mmHg}$ or diastolic blood pressure $(\mathrm{DBP}) \geq 90 \mathrm{mmHg}$ at both the screening and recruitment visit, or who were on anti-hypertensive medication. The major exclusion criteria included history of physiciandiagnosed stroke, myocardial infarction (MI), heart failure, post-coronary revascularization, and/or congenital heart disease, and/or current supplementation by folic acid, vitamin B12 or vitamin B6.

In the CSPPT, a total of 20,702 eligible participants were enrolled. Our current study is a post-hoc analysis of the CSPPT, including a total of 14,393 participants with complete major data and who were free of diabetes [physician-diagnosed diabetes or using glucose-lowering drugs or fasting glucose (FG) was $<7.0 \mathrm{mmol} / \mathrm{L}$ (126 mg/ $\mathrm{dL}$ )], as well as without liver disease (self-reported chronic hepatitis, hepatic adipose infiltration, or cirrhosis) at baseline (Fig. 1).

\section{Intervention and follow-up}

Eligible participants were randomized to receive a daily oral dose of 1 tablet containing $10 \mathrm{mg}$ enalapril and $0.8 \mathrm{mg}$ folic acid (single pill combination, the enalaprilfolic acid group) or one tablet containing $10 \mathrm{mg}$ enalapril only (the enalapril-only group).

Participants were scheduled for follow-up every 3 months. At each follow-up visit, BP was measured; study drug compliance, concomitant medication use, adverse events and possible endpoint events were documented by trained research staff and physicians.

\section{Laboratory assessment}

Serum fasting ALP, gamma glutamyl transpeptidase (GGT), alanine aminotransferase (ALT), aspartate aminotransferase (AST), total homocysteine (tHcy), creatinine, lipids and fasting glucose (FG) were measured with the use of automatic clinical analyzers (Beckman Coulter) at the core laboratory of the National Clinical Research Center for Kidney Disease, Nanfang Hospital, Guangzhou, China. Serum folate at baseline were measured by a commercial lab using a chemiluminescent immunoassay (New Industrial, Shenzhen, China). Estimated glomerular filtration rate (eGFR) was calculated using the Chronic Kidney Disease Epidemiology Collaboration (CKD-EPI) equation [23].

\section{Study outcomes}

The primary study outcome was new-onset diabetes, defined as physician-diagnosed diabetes, or use of glucose-lowering drugs during follow-up, or new onset $\mathrm{FG} \geq 7.0 \mathrm{mmol} / \mathrm{L}(126 \mathrm{mg} / \mathrm{dL})$ at the exit visit. In China, the clinical diagnosis and treatment of diabetes used the same criteria according to the China guideline for diabetes $[24,25]$.

The secondary study outcome was new-onset impaired fasting glucose (IFG), defined as $\mathrm{FG}<6.1 \mathrm{mmol} / \mathrm{L}$ 


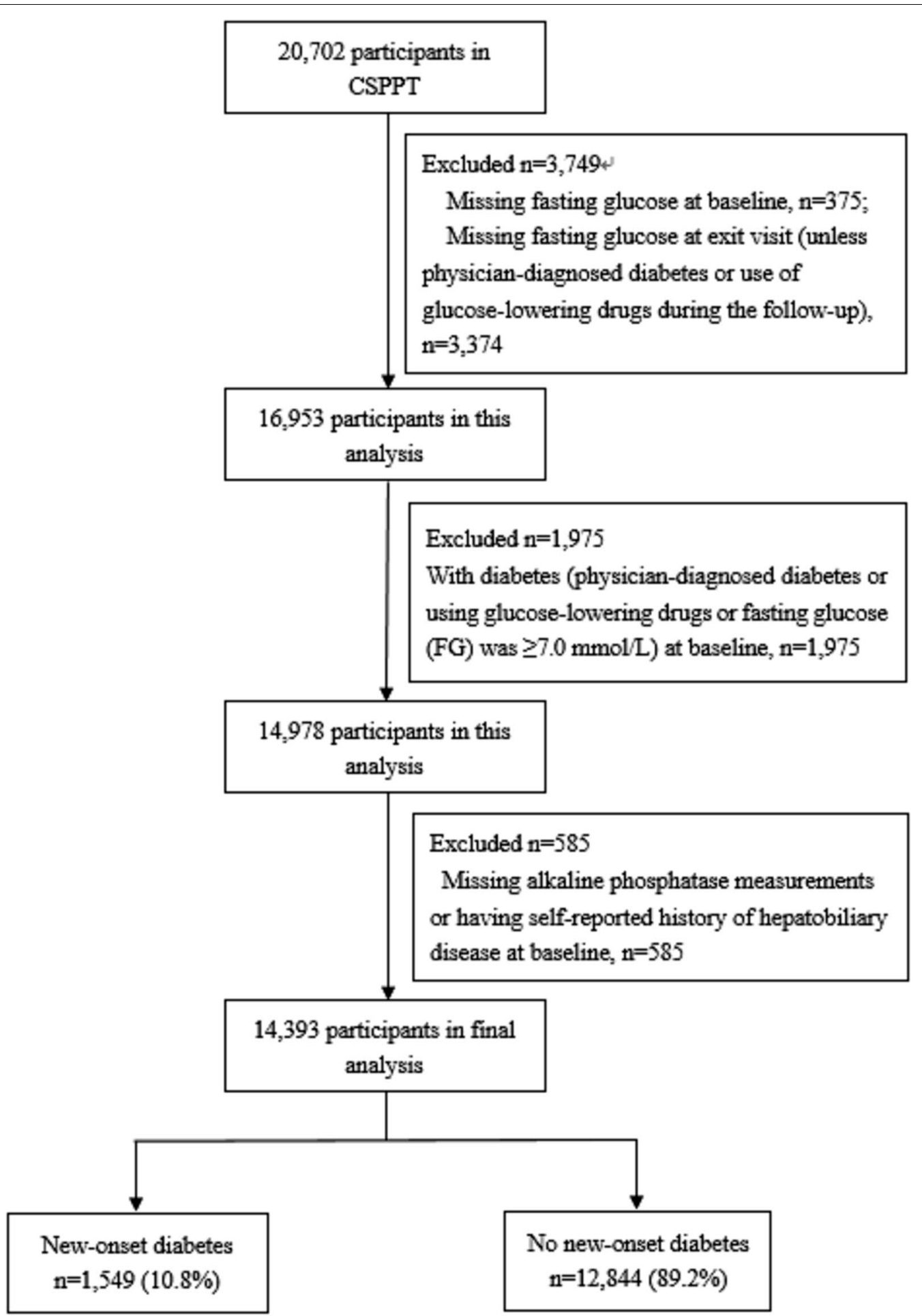

Fig. 1 Flow chart of the participants 
$(110 \mathrm{mg} / \mathrm{dL})$ at baseline and $\geq 6.1 \mathrm{mmol} / \mathrm{L}$ but $<7.0 \mathrm{mmol} / \mathrm{L}$ at the exit visit. The analysis of newonset IFG included subjects whose FG $<6.1 \mathrm{mmol} / \mathrm{L}$ and without new-onset diabetes during the follow-up.

\section{Statistical analysis}

Baseline characteristics are presented as means \pm standard deviations (SDs) or medians [interquartile range (IQR)] for continuous variables and proportions for categorical variables. Statistical significance of differences in baseline characteristics was assessed in accordance with baseline serum ALP quartiles $(<79,79$ to $<96,96$ to $<116$, and $\geq 116 \mathrm{IU} / \mathrm{L}$ ) using ANOVA tests, signed rank tests or chi-square tests, accordingly.

We first explored the association between serum ALP and new-onset diabetes using thin plate regression splines in generalized additive models implemented by the $\mathrm{R}$ package $m g c v$. Then multivariable logistic regression models [odds ratio (OR) and 95\% confidence interval (CI)] were used to evaluate relation of serum ALP with new-onset diabetes and new-onset IFG, without and with adjustment for age, sex, study center, treatment group, body mass index (BMI), smoking, alcohol drinking, family history of diabetes, SBP, FG, total cholesterol (TC), triglycerides (TG), eGFR, folate, tHcy and the use of antihypertensive drugs at baseline, as well as time-averaged SBP during the treatment period. As additional exploratory analyses, possible modifications on the association between serum ALP and new-onset diabetes were also evaluated by stratified analyses and interaction testing.

A two-tailed $P<0.05$ was considered statistically significant in all analyses. R software, version 3.6.3 (https:// www.R-project.org/) was used to perform all statistical analyses.

\section{Results}

\section{Study participants and baseline characteristics}

In this study, a total of 14,393 participants with complete major data and without diabetes and liver disease at baseline, were included in the final analyses (Fig. 1).

Baseline characteristics of participants by baseline ALP quartiles are presented in Table 1. The mean and median serum ALP levels were $100 \mathrm{IU} / \mathrm{L}$ (SD, 30.5) and 96 IU/L, respectively. Participants with higher ALP levels were older and more likely to be female; had higher SBP, TG, high-density lipoprotein (HDL) cholesterol, FG, folate levels at baseline and time-averaged on-treatment SBP during the treatment period; lower BMI, DBP, TC, tHcy levels at baseline and time-averaged on-treatment DBP during the treatment period; and lower frequency in use of antihypertensive drugs and antiplatelet drugs at baseline, as wells as lower frequency of current smoking, alcohol drinking and family history of diabetes (Table 1).

In addition, during the treatment period, participants with higher ALP levels had higher frequency in use of calcium channel blockers; lower frequency in use of diuretics and antiplatelet drugs. (Table 2).

\section{Association between baseline serum ALP and study outcomes}

During median follow-up of 4.5 years (IQR, 4.24.7 years), 1549 (10.8\%) participants developed newonset diabetes. In our current study, a total of 1549 participants developed diabetes. Of these, 156 were those with physician-diagnosed diabetes, 41 reported with the use of glucose-lowering drugs during follow-up, and 1448 had a new-onset FG $\geq 7.0 \mathrm{mmol} / \mathrm{L}$ at the exit visit. Some of the patients met at least two of the above three criteria.

Overall, there was a positive relation of serum ALP and the risk of new-onset diabetes (per SD increment, adjusted OR, 1.07; 95\% CI: 1.01, 1.14) (Fig. 2a), and newonset IFG (per SD increment, adjusted OR, 1.07; 95\% CI: 1.02, 1.14) (Fig. 2b). Consistently, compared with participants with serum ALP $<96$ IU/L (median), significantly higher risks of new-onset diabetes (adjusted OR, 1.13; 95\% CI: 1.00, 1.27) and new-onset IFG (adjusted OR, 1.13; $95 \%$ CI: $1.02,1.27)$ were found in those with serum ALP $\geq 96 \mathrm{IU} / \mathrm{L}$ (Table 3). Accordingly, we also found a positive association between serum ALP and change in FG levels (FG level at exit visit minus that at baseline; per SD increment, adjusted $\beta, 0.03 \mathrm{mmol} / \mathrm{L} ; 95 \% \mathrm{CI}$ : 0.01 , 0.06) (Fig. 3).

Similar results were also found when estimating the association between baseline ALP and new-onset diabetes with risk ratio (RR) (per SD increment; adjusted RR, 1.06; 95\% CI: 1.00, 1.12) (Table 4), or in participants with a normal range of baseline serum ALP (20-140 IU/L) [26] levels (per SD increment; adjusted OR, 1.07; 95\% CI: 1.01, 1.14) (Fig. 4). More importantly, further adjustment for use of calcium channel blockers, diuretics and antiplatelet drugs during the treatment period (per SD increment; adjusted OR, 1.07; 95\% CI: 1.01, 1.14) (Table 5), or other liver enzymes, including GGT, ALT, AST (per SD increment; adjusted OR, 1.06; 95\% CI: 1.00, 1.13) (Table 6) did not substantially change the results.

\section{Association between change in serum ALP and new-onset diabetes}

In order to further examine the association between serum ALP and new-onset diabetes, we investigated the relation of change in ALP with new-onset diabetes. We categorized the participants into four groups according to median of baseline serum ALP (96 IU/L): persistently low ALP levels (<96 IU/L at both baseline and exit visit), 
Table 1 Characteristics of the study participants by baseline serum alkaline phosphatase (ALP) quartiles

\begin{tabular}{|c|c|c|c|c|c|}
\hline \multirow[t]{2}{*}{ Variables $^{*}$} & \multicolumn{4}{|c|}{ Serum ALP, IU/L } & \multirow[t]{2}{*}{$P$ value $^{\dagger}$} \\
\hline & Q1 (<79) & Q2 (79-<96) & Q3 (96-<116) & $\mathrm{Q} 4(\geq 116)$ & \\
\hline N & 3486 & 3623 & 3577 & 3707 & \\
\hline Age, yr & $58.3 \pm 8.1$ & $59.7 \pm 7.5$ & $60.7 \pm 7.1$ & $61.3 \pm 6.6$ & $<0.001$ \\
\hline Male, no. (\%) & $1773(50.9)$ & $1609(44.4)$ & $1377(38.5)$ & $1059(28.6)$ & $<0.001$ \\
\hline Body mass index, $\mathrm{kg} / \mathrm{m}^{2}$ & $25.4 \pm 3.6$ & $25.1 \pm 3.6$ & $24.8 \pm 3.6$ & $24.4 \pm 3.7$ & $<0.001$ \\
\hline Current smoking, no. (\%) & $963(27.6)$ & $938(25.9)$ & $810(22.6)$ & $664(17.9)$ & $<0.001$ \\
\hline Current drinking, no. (\%) & $1143(32.8)$ & $949(26.2)$ & $778(21.8)$ & $567(15.3)$ & $<0.001$ \\
\hline Family history of diabetes, no. (\%) & $151(4.3)$ & $145(4.0)$ & $125(3.5)$ & $116(3.1)$ & 0.036 \\
\hline Enalapril group, no. (\%) & $1727(49.5)$ & $1838(50.7)$ & $1800(50.3)$ & $1850(49.9)$ & 0.769 \\
\hline \multicolumn{6}{|l|}{$\mathrm{BP}, \mathrm{mmHg}$} \\
\hline SBP at baseline & $165.6 \pm 20.5$ & $167.2 \pm 20.4$ & $167.5 \pm 20.5$ & $168.2 \pm 20.3$ & $<0.001$ \\
\hline DBP at baseline & $95.4 \pm 11.9$ & $94.5 \pm 11.9$ & $94.3 \pm 11.8$ & $93.3 \pm 11.7$ & $<0.001$ \\
\hline Time-averaged SBP & $138.4 \pm 10.6$ & $139.1 \pm 10.3$ & $138.8 \pm 10.6$ & $139 \pm 10.6$ & 0.022 \\
\hline Time-averaged DBP & $84.1 \pm 7.2$ & $83.3 \pm 7.2$ & $82.6 \pm 7.0$ & $81.7 \pm 7.3$ & $<0.001$ \\
\hline \multicolumn{6}{|l|}{ Laboratory results, $\mathrm{mmol} / \mathrm{L}$} \\
\hline Total cholesterol & $5.6 \pm 1.1$ & $5.6 \pm 1.1$ & $5.5 \pm 1.1$ & $5.3 \pm 1.1$ & $<0.001$ \\
\hline Triglycerides & $1.6 \pm 1.9$ & $1.6 \pm 0.9$ & $1.6 \pm 0.9$ & $1.7 \pm 0.9$ & $<0.001$ \\
\hline HDL cholesterol & $1.3 \pm 0.4$ & $1.3 \pm 0.4$ & $1.4 \pm 0.4$ & $1.4 \pm 0.4$ & $<0.001$ \\
\hline Fasting glucose & $5.5 \pm 0.7$ & $5.4 \pm 0.7$ & $5.4 \pm 0.7$ & $5.3 \pm 0.7$ & $<0.001$ \\
\hline $\mathrm{eGFR}, \mathrm{mL} / \mathrm{min} 1.73 / \mathrm{m}^{2}$ & $93.7 \pm 13.1$ & $93.8 \pm 12.8$ & $93.3 \pm 12.1$ & $93.6 \pm 12.2$ & 0.455 \\
\hline Folate, ng/mL & $7.8 \pm 3.3$ & $8.2 \pm 3.8$ & $8.5 \pm 3.8$ & $9.3 \pm 4.4$ & $<0.001$ \\
\hline Total homocysteine, $\mu \mathrm{mol} / \mathrm{L}$ & $14.9 \pm 9.9$ & $14.5 \pm 8.8$ & $14.5 \pm 8.0$ & $14.1 \pm 6.9$ & $<0.001$ \\
\hline Alkaline phosphatase, IU/L & $66.1 \pm 10.4$ & $87.1 \pm 4.8$ & $104.9 \pm 5.8$ & $140.0 \pm 24.1$ & $<0.001$ \\
\hline Aspartate transaminase, IU/L & $21.4(18.0,26.0)$ & $22.7(19.2,27.8)$ & $24.0(20.1,29.5)$ & $26.7(21.9,33.1)$ & $<0.001$ \\
\hline Alanine transaminase, IU/L & $11.0(8.0,14.1)$ & $12.0(9.0,16.0)$ & $12.8(10.0,17.0)$ & $14.0(11.0,19.0)$ & $<0.001$ \\
\hline Gamma glutamyl transpeptidase, IU/L & $19.1(14.3,27.6)$ & 19.3(14.6,27.5) & 19.3(14.6,28.1) & $19.9(14.9,28.7)$ & 0.005 \\
\hline \multicolumn{6}{|l|}{ Medication use, no. (\%) } \\
\hline Antihypertensive drugs & $1794(51.5)$ & $1708(47.1)$ & $1621(45.3)$ & $1531(41.3)$ & $<0.001$ \\
\hline Lipid lowering drugs & $37(1.1)$ & $26(0.7)$ & $19(0.5)$ & $25(0.7)$ & 0.065 \\
\hline Antiplatelet drugs & $161(4.6)$ & $109(3.0)$ & $102(2.9)$ & $71(1.9)$ & $<0.001$ \\
\hline
\end{tabular}

$A L P$ serum alkaline phosphatase, $D B P$ diastolic blood pressure, eGFR estimated glomerular filtration rate, $H D L$ high-density lipoprotein, $S B P$ systolic blood pressure

* Continuous variables are presented as Mean \pm SD or IQR $(25,75$ th), categorical variables are presented as $n(\%)$

+ Difference between any 2 groups

Table 2 Concomitant medication usage during the treatment period by baseline serum alkaline phosphatase quartiles

\begin{tabular}{|c|c|c|c|c|c|}
\hline \multirow[t]{2}{*}{ Variables $^{*}$} & \multicolumn{4}{|c|}{ Baseline serum alkaline phosphatase quartiles, IU/L } & \multirow[t]{2}{*}{$P$ value $^{\dagger}$} \\
\hline & Q1 (<79) & Q2 (79-<96) & Q3 $(96-<116)$ & $\mathrm{Q} 4(\geq 116)$ & \\
\hline N & 3486 & 3623 & 3577 & 3707 & \\
\hline \multicolumn{6}{|l|}{ Antihypertensive drugs } \\
\hline Calcium channel blockers & $2804(80.4)$ & $2954(81.5)$ & $2958(82.7)$ & $3110(83.9)$ & $<0.001$ \\
\hline Diuretics & $2011(57.7)$ & $2028(56.0)$ & $1901(53.1)$ & $1750(47.2)$ & $<0.001$ \\
\hline Lipid-lowering drugs & $5(0.1)$ & $3(0.1)$ & $6(0.2)$ & $5(0.1)$ & 0.790 \\
\hline Antiplatelet drugs & $33(0.9)$ & $35(1.0)$ & $26(0.7)$ & $17(0.5)$ & 0.045 \\
\hline
\end{tabular}

\footnotetext{
* Regular concomitant medication usage was defined as 180 or more cumulative days of taking the drug of interest

+ Difference between any 2 groups
} 

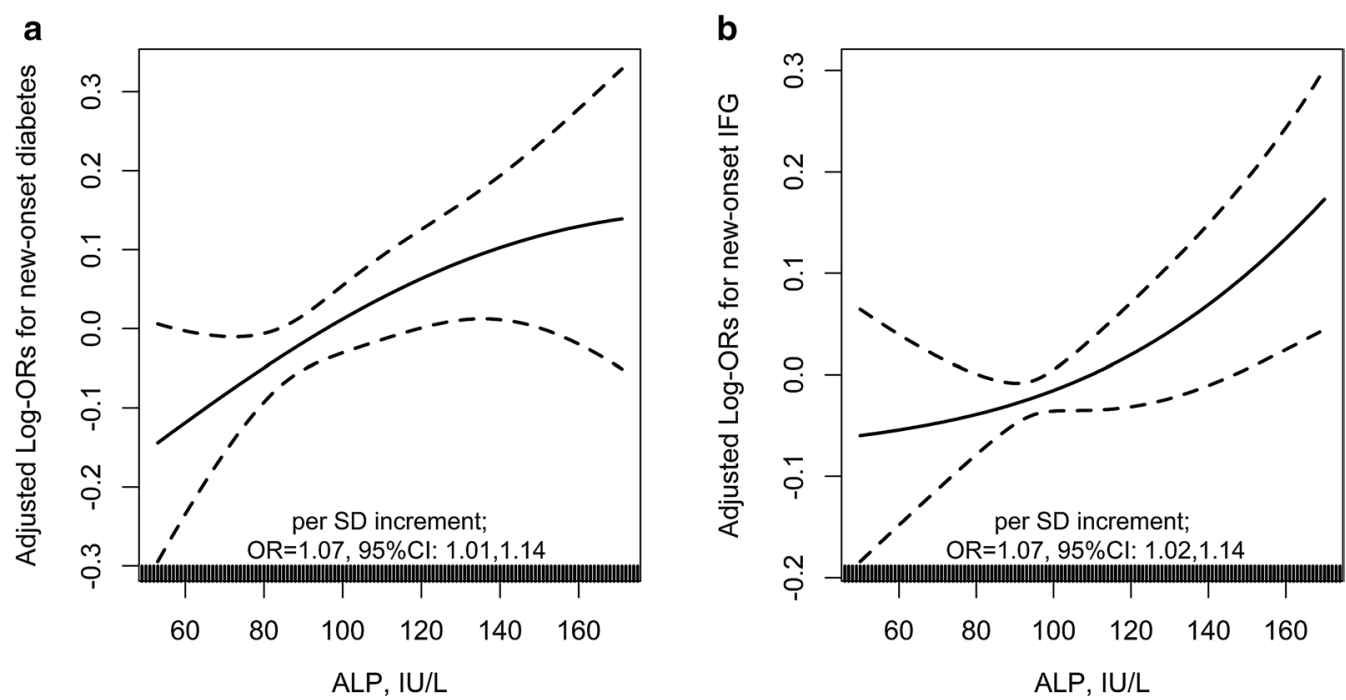

Fig. 2 The association between baseline serum alkaline phosphatase (ALP) and new-onset diabetes $\mathbf{a}$ and new-onset impaired fasting glucose (IFG) b in hypertensive adults. Adjusted for age, sex, study center, treatment group, body mass index (BMI), smoking, alcohol drinking, family history of diabetes, SBP, fasting glucose (FG), total cholesterol (TC), triglycerides (TG), eGFR, folate, total homocysteine and the use of antihypertensive drugs at baseline, as well as time-averaged SBP during the treatment period. Subjects with baseline $\mathrm{FG}<6.1 \mathrm{mmol} / \mathrm{L}$ and without new-onset diabetes during follow-up were included in the analysis for new-onset IFG

persistently high ALP levels ( $\geq 96 \mathrm{IU} / \mathrm{L}$ at both baseline and exit visit), decreased ALP levels ( $\geq 96 \mathrm{IU} / \mathrm{L}$ at baseline and $<96 \mathrm{IU} / \mathrm{L}$ at exit visit), and increased ALP levels $(<96 \mathrm{IU} / \mathrm{L}$ at baseline and $\geq 96 \mathrm{IU} / \mathrm{L}$ at exit visit).

The incidence rates of new-onset diabetes in participants with persistently low ALP levels, persistently high ALP levels, decreased ALP levels, and increased ALP levels were 9.0, 12.6, 8.6 and $16.3 \%$, respectively. Comparted with those with persistently low ALP levels, a significantly higher risk of new-onset diabetes was found in participants with persistently high ALP levels (adjusted OR, 1.57; 95\% CI: 1.36, 1.81) or increased ALP levels (adjusted OR, 1.97; 95\% CI: 1.61, 2.42); however, the adjusted odds ratio $(95 \% \mathrm{CI})$ for those decreased ALP levels with was $0.96(0.81,1.14)$ (Table 7$)$.

\section{Stratified analyses}

In the stratified analyses, a stronger positive association between baseline ALP with new-onset diabetes was found in participants with tHcy $<10 \mu \mathrm{mol} / \mathrm{L}$ (per SD increment; adjusted OR, 1.24; $95 \%$ CI: $1.10,1.40$ vs. $\geq 10 \mu \mathrm{mol} / \mathrm{L}$ : adjusted OR, 1.03; 95\% CI: 0.96, 1.10; $P$-interaction $=0.007$ ) and $\mathrm{FG} \geq 5.9 \mathrm{mmol} / \mathrm{L}$ (quartile 3 ) (per SD increment; adjusted OR, 1.16; 95\% CI: 1.07, 1.27 vs. $<5.9 \mathrm{mmol} / \mathrm{L}$ : adjusted OR, 1.00 ; $95 \% \mathrm{CI}$ : $0.93,1.08$; $P$-interaction $=0.009)$ (Fig. 5).

However, other variables, including sex (male vs. female), age ( $<60$ vs. $\geq 60$ years), BMI ( $<24 \mathrm{vs.} \geq 24 \mathrm{~kg} /$ $\mathrm{m}^{2}$ ), treatment group (enalapril vs. enalapril-folic acid), current smoking (no vs. yes), current alcohol drinking (no vs. yes), SBP (<160 vs. $\geq 160 \mathrm{mmHg}$ ), TC levels ( $<5.2$ vs. $\geq 5.2 \mathrm{mmol} / \mathrm{L})$ at baseline, as well as time-averaged SBP (<140 vs. $\geq 140 \mathrm{mmHg}$ ), calcium channel blockers usage (no vs. yes) and diuretics usage (no vs. yes) over the trial period, did not significantly modified the association between baseline serum ALP and new-onset diabetes (all $P$-interactions $>0.05$ ) (Fig. 5).

\section{Discussion}

Our study demonstrated that there was a positive association between baseline serum ALP levels and new-onset diabetes, independent of other liver aminotransferases, treated BP and other important confounders, among hypertensive patients. Moreover, our study expanded the results of previous studies by demonstrating that the positive association between baseline serum ALP levels and new-onset diabetes was more pronounced in participants with lower tHcy or higher FG levels.

\section{Comparisons with previous studies}

Previous studies have linked serum ALP levels and the risk of diabetes, but reported controversial results. In a case-control study, Malo MS reported that high intestinal alkaline phosphatase (IAP) levels appeared to be protective against diabetes irrespective of obesity [27]. However, Nannipieri M et al. $(\mathrm{n}=1441)$ [11], Nakanishi $\mathrm{N}$ et al. $(\mathrm{n}=3260)$ [12], and Hanley AJ et al. $(\mathrm{n}=906)$ [13] 
Table 3 The association between baseline serum alkaline phosphatase (ALP) and study outcomes

\begin{tabular}{|c|c|c|c|c|c|c|}
\hline \multirow[t]{2}{*}{ ALP, IU/L } & \multirow[t]{2}{*}{$\mathrm{N}$} & \multirow[t]{2}{*}{ No. of events (\%) } & \multicolumn{2}{|l|}{ Crude model } & \multicolumn{2}{|c|}{ Adjusted model* } \\
\hline & & & OR $(95 \% \mathrm{CI})$ & $P$ value $^{\ddagger}$ & OR (95\% Cl) & $P$ value $^{\ddagger}$ \\
\hline \multicolumn{7}{|l|}{ New-onset diabetes } \\
\hline $\begin{array}{l}\text { Continuous, per SD } \\
(30.5 \mathrm{IU} / \mathrm{L}) \text { incre- } \\
\text { ment }\end{array}$ & 14,393 & $1549(10.8)$ & $1.07(1.02,1.13)$ & 0.007 & $1.07(1.01,1.14)$ & 0.027 \\
\hline \multicolumn{7}{|l|}{ Quartiles } \\
\hline Q1 (<79) & 3486 & $343(9.8)$ & 1.00 (ref.) & & 1.00 (ref.) & \\
\hline Q2 (79-<96) & 3623 & $381(10.5)$ & $1.08(0.92,1.26)$ & 0.346 & $1.09(0.93,1.28)$ & 0.291 \\
\hline Q3 $(96-<116)$ & 3577 & $390(10.9)$ & $1.12(0.96,1.31)$ & 0.143 & $1.14(0.96,1.34)$ & 0.130 \\
\hline Q4 ( $\geq 116)$ & 3707 & $435(11.7)$ & $1.22(1.05,1.42)$ & 0.010 & $1.24(1.05,1.48)$ & 0.013 \\
\hline$P$ for trend & & & 0.009 & & 0.013 & \\
\hline \multicolumn{7}{|l|}{ Categories } \\
\hline Q1-2 (<96) & 7109 & $724(10.2)$ & 1.00 (ref.) & & 1.00 (ref.) & \\
\hline Q3-4 ( $\geq 96)$ & 7284 & $825(11.3)$ & $1.13(1.01,1.25)$ & 0.027 & $1.13(1.00,1.27)$ & 0.046 \\
\hline \multicolumn{7}{|l|}{ New-onset $\mathrm{IFG}^{+}$} \\
\hline $\begin{array}{l}\text { Continuous, per SD } \\
(30.8 \mathrm{IU} / \mathrm{L}) \text { incre- } \\
\text { ment }\end{array}$ & 11,062 & $1876(17.0)$ & $1.04(0.99,1.09)$ & 0.105 & $1.07(1.02,1.14)$ & 0.012 \\
\hline \multicolumn{7}{|l|}{ Quartiles } \\
\hline Q1 (<79) & 2629 & $446(17.0)$ & 1.00 (ref.) & & 1.00 (ref.) & \\
\hline Q2 (79-<96) & 2788 & $446(16.0)$ & $0.93(0.81,1.08)$ & 0.337 & $0.94(0.81,1.09)$ & 0.415 \\
\hline Q3 (96-<117) & 2825 & $487(17.2)$ & $1.02(0.89,1.17)$ & 0.788 & $1.06(0.91,1.23)$ & 0.431 \\
\hline Q4 ( $\geq 117)$ & 2820 & $497(17.6)$ & $1.05(0.91,1.21)$ & 0.520 & $1.14(0.97,1.34)$ & 0.101 \\
\hline$P$ for trend & & & 0.302 & & 0.042 & \\
\hline \multicolumn{7}{|l|}{ Categories } \\
\hline Q1-2 (<96) & 5417 & $892(16.5)$ & 1.00 (ref.) & & 1.00 (ref.) & \\
\hline Q3-4 ( $\geq 96)$ & 5645 & $984(17.4)$ & $1.07(0.97,1.18)$ & 0.177 & $1.13(1.02,1.27)$ & 0.024 \\
\hline
\end{tabular}

$A L P$ serum alkaline phosphatase, $C l$ confidence interval, eGFR estimated glomerular filtration rate, IFG impaired fasting glucose, $O R$ odds ratio, SD standard deviations, SBP systolic blood pressure

${ }^{*}$ Adjusted for age, sex, study center, treatment group, body mass index (BMI), smoking, alcohol drinking, family history of diabetes, SBP, fasting glucose (FG), total cholesterol (TC), triglycerides (TG), eGFR, folate, total homocysteine and the use of antihypertensive drugs at baseline, as well as time-averaged SBP during the treatment period

+ Subjects with baseline $\mathrm{FG}<6.1 \mathrm{mmol} / \mathrm{L}$ and without new-onset diabetes during follow-up were included in the analysis

* In comparison with the first quartile

found that there was no significant association between ALP and incident diabetes. Moreover, a study conducted in Taiwan [14], including 132,377 non-diabetic individuals, showed that higher ALP level was significantly related to increased risk of diabetes. Of note, this study did not consider the effect of some major risk factors for diabetes, such as initial FG levels and the concomitant medications, and therefore, could not provide an accurate measurement of the association between ALP and incident diabetes. In addition, a recent mendelian randomization study demonstrated that there was a modest negative effect of genetically predicted ALP on type 2 diabetes (OR, 0.91; 95\% CI: 0.86, 0.97) [28]. At the same time, another mendelian randomization study suggested that ALP was not associated with the risk of diabetes
[29]. It must be pointed out that both studies [28, 29] only included European origin participants whose genetic background may be different with other population. Overall, to data, the association between ALP and incident diabetes remains uncertain. The explanations for these discrepant results might be due to differences in study population characteristics and/or sample sizes. More importantly, no previous study has comprehensively investigated the modifiers on the relation of ALP with new-onset diabetes.

\section{Study strengths and possible mechanisms}

Our study provided a rare opportunity to evaluate the temporal and dose-response relation of serum ALP with new-onset diabetes in hypertension adults, with 


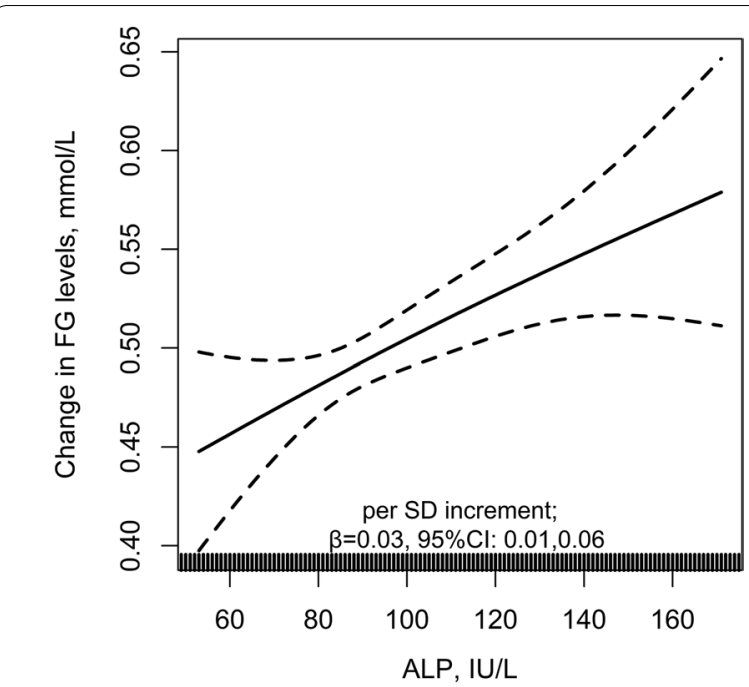

Fig. 3 The association between baseline serum alkaline phosphatase (ALP) and change in FG levels. Adjusted for age, sex, study center, treatment group, body mass index (BMI), smoking, alcohol drinking, family history of diabetes, SBP, fasting glucose (FG), total cholesterol (TC), triglycerides (TG), eGFR, folate, total homocysteine and the use of antihypertensive drugs at baseline, as well as time-averaged SBP during the treatment period. The analysis was only included subjects without physician-diagnosed diabetes, or use of glucose-lowering drugs during follow-up

a comprehensive adjustment and stratified analysis for almost all the pertinent clinical information and laboratory measurements. This is the first study of this kind in a hypertensive population. Our study has made some new contributions to the field. First, we demonstrated that higher serum ALP associated with increased new-onset diabetes in hypertensive patients, independent of other liver enzymes, treated BP and traditional or suspected risk factors. Our study findings are biological plausible based on available literature, although the potential mechanisms by which serum ALP increases diabetes risk remains to be delineated. (1) ALP was reported to contribute to vascular calcification [30], which linked to insulin resistance, subsequently leading to the development of diabetes [31]. Animal experiments showed that ALP upregulation was demonstrated in the vascular wall of diabetic rat and mouse models of vascular calcification [32]. (2) Higher serum ALP was associated with increased risk of endothelial dysfunction, a process related to insulin resistance, an initial process to diabetes [33]. This was explained that ALP could reduce nitric oxide (NO) bioavailability by inhibiting tyrosine kinase activity into endothelial cells [34], leading to the consequent impairment of endothelial NO synthase function [35]. (3) Higher serum ALP levels had been reported to be associated with increased inflammation status in CKD patients or general population [36, 37]. Notably, both endothelial dysfunction [38, 39] and chronic inflammation [40,41] has been considered as the early events in the development of the diabetes. Taken together, the aforementioned biological functions of ALP may be in part underlying our observed positive association between ALP and incident diabetes. However, more mechanistic studies are still needed.

Second, our results showed that tHcy and FG levels significantly modified the association between serum ALP and the risk of new-onset diabetes. A stronger association was found in those with lower

Table 4 Estimating the association between baseline serum alkaline phosphatase (ALP) and new-onset diabetes evaluated with risk ratio (RR)

\begin{tabular}{|c|c|c|c|c|c|c|}
\hline \multirow[t]{2}{*}{ ALP, IU/L } & \multirow[t]{2}{*}{$\mathrm{N}$} & \multirow[t]{2}{*}{ No. of events (\%) } & \multicolumn{2}{|l|}{ Crude model } & \multicolumn{2}{|c|}{ Adjusted model* } \\
\hline & & & $\mathrm{RR}(95 \% \mathrm{Cl})$ & $P$ value $^{\dagger}$ & $\mathrm{RR}(95 \% \mathrm{Cl})$ & $P$ value ${ }^{\dagger}$ \\
\hline \multicolumn{7}{|l|}{ New-onset diabetes } \\
\hline $\begin{array}{l}\text { Continuous, per SD } \\
(30.5 \mathrm{IU} / \mathrm{L}) \text { increment }\end{array}$ & 14,393 & $1549(10.8)$ & $1.06(1.01,1.12)$ & 0.011 & $1.06(1.00,1.12)$ & 0.034 \\
\hline \multicolumn{7}{|l|}{ Quartiles } \\
\hline Q1 (<79) & 3486 & $343(9.8)$ & 1.00 (ref.) & & 1.00 (ref.) & \\
\hline Q2 (79-<96) & 3623 & $381(10.5)$ & $1.07(0.93,1.24)$ & 0.372 & $1.09(0.94,1.26)$ & 0.274 \\
\hline Q3 $(96-<116)$ & 3577 & $390(10.9)$ & $1.12(0.97,1.29)$ & 0.166 & $1.12(0.96,1.30)$ & 0.143 \\
\hline Q4 ( $\geq 116)$ & 3707 & $435(11.7)$ & $1.19(1.04,1.38)$ & 0.015 & $1.21(1.03,1.41)$ & 0.018 \\
\hline$P$ for trend & & & 0.013 & & 0.019 & \\
\hline
\end{tabular}

$A L P$ serum alkaline phosphatase, $C l$ confidence interval, eGFR estimated glomerular filtration rate, $R R$ risk ratio, $S D$ standard deviations, $S B P$ systolic blood pressure ${ }^{*}$ Adjusted for age, sex, study center, treatment group, body mass index (BMI), smoking, alcohol drinking, family history of diabetes, SBP, fasting glucose (FG), total cholesterol (TC), triglycerides (TG), eGFR, folate, total homocysteine and the use of antihypertensive drugs at baseline, as well as time-averaged SBP during the treatment period

+ In comparison with the first quartile 


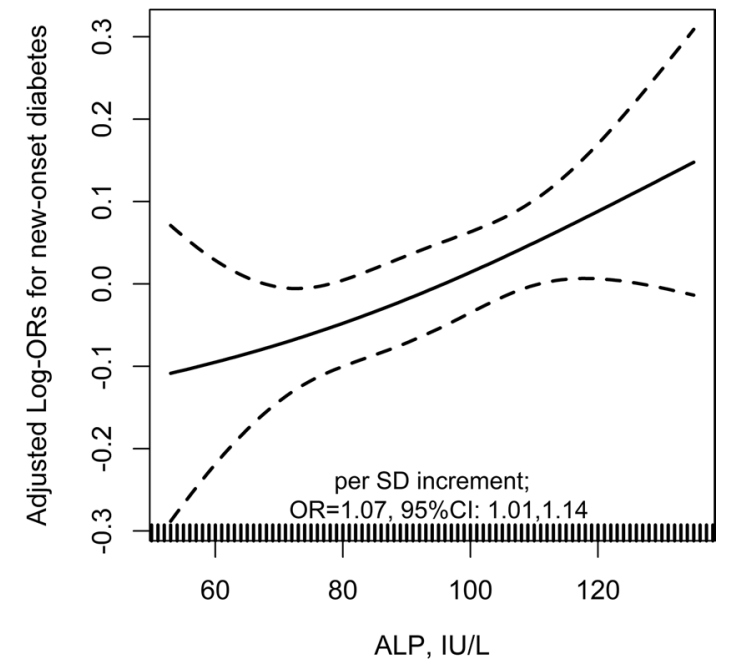

Fig. 4 The association between baseline alkaline phosphatase (ALP) and new-onset diabetes in normal ALP levels (20-140 IU/L). Adjusted for age, sex, study center, treatment group, body mass index (BMI), smoking, alcohol drinking, family history of diabetes, SBP, fasting glucose (FG), total cholesterol (TC), triglycerides (TG), eGFR, folate, total homocysteine and the use of antihypertensive drugs at baseline, as well as time-averaged SBP during the treatment period

tHcy $(<10 \mu \mathrm{mol} / \mathrm{L})$ or higher FG $(\geq 5.9 \mathrm{mmol} / \mathrm{L})$ levels at baseline. The higher FG levels may partially represent the abnormal glucose metabolic state, due to the impairment of pancreatic alpha and beta cell function and the induced impaired insulin secretion [42, 43]. This population usually had a significantly increased risk of diabetes [44]. Since higher ALP was mainly associated with insulin resistance, our results suggested that increased ALP and higher FG levels may synergistically increase the risk of incident diabetes. On the other hand, it had been reported that elevated tHcy could also promote the calcification of vessels [45], and was related to endothelial dysfunction, inflammation and oxidative stress $[15,46,47]$. It seemed that elevated tHcy and ALP levels may share some common pathway in the development of diabetes. As such, the detrimental effects of higher tHcy levels may attenuate the positive relation of serum ALP levels with the risk of diabetes. Our studies suggested that the combination of optimal ALP, tHcy and FG levels may be a better strategy for the primary prevention of diabetes in hypertensive adults. However, further studies are warranted to verify this hypothesis and further examine the underlying mechanisms.

\section{Limitations}

Our study has some limitations. First, this is a posthoc analysis. Although our current study adjusted for a broad array of covariates in the regression models, the possibility of residual confounding cannot be excluded. Second, we did not measure glycosylated hemoglobin A1c and insulin or perform glucose tolerance tests. However, our definition of diabetes was similar to that of previous studies $[48,49]$. In addition, the FG levels were assessed only at baseline and the exit visit. More frequent assays of FG levels would allow for a more accurate assessment of its progression over time. Third, in the current study, we collected total serum ALP

Table 5 The association between baseline serum alkaline phosphatase (ALP) and new-onset diabetes, with further adjustment for the use of calcium channel blockers, diuretics and antiplatelet drugs during the treatment period

\begin{tabular}{|c|c|c|c|c|c|c|}
\hline \multirow[t]{2}{*}{ ALP, IU/L } & \multirow[t]{2}{*}{$\mathbf{N}$} & \multirow[t]{2}{*}{ No. of events (\%) } & \multicolumn{2}{|l|}{ Crude model } & \multicolumn{2}{|c|}{ Adjusted model* } \\
\hline & & & OR (95\% Cl) & $P$ value $^{\dagger}$ & OR (95\% Cl) & $P$ value ${ }^{\dagger}$ \\
\hline $\begin{array}{l}\text { Continuous, per SD } \\
\text { increment }\end{array}$ & 14,393 & 1549 (10.8) & $1.07(1.02,1.13)$ & 0.007 & $1.07(1.01,1.14)$ & 0.026 \\
\hline \multicolumn{7}{|l|}{ Quartiles } \\
\hline Q1 (<79) & 3486 & $343(9.8)$ & 1.00 (ref.) & & 1.00 (ref.) & \\
\hline Q2 $(79-<96)$ & 3623 & $381(10.5)$ & $1.08(0.92,1.26)$ & 0.346 & $1.09(0.93,1.28)$ & 0.290 \\
\hline Q3 $(96-<116)$ & 3577 & $390(10.9)$ & $1.12(0.96,1.31)$ & 0.143 & $1.14(0.96,1.34)$ & 0.127 \\
\hline $\mathrm{Q} 4(\geq 116)$ & 3707 & $435(11.7)$ & $1.22(1.05,1.42)$ & 0.010 & $1.24(1.05,1.48)$ & 0.013 \\
\hline$P$ for trend & & & 0.009 & & 0.013 & \\
\hline
\end{tabular}

ALP serum alkaline phosphatase, $C l$ confidence interval, eGFR estimated glomerular filtration rate, OR odds ratio, $S D$ standard deviations, $S B P$ systolic blood pressure *Adjusted for age, sex, study center, treatment group, body mass index (BMI), smoking, alcohol drinking, family history of diabetes, SBP, fasting glucose (FG), total cholesterol (TC), triglycerides (TG), eGFR, folate, total homocysteine and the use of antihypertensive drugs at baseline, as well as time-averaged SBP, the use of calcium channel blockers, diuretics and antiplatelet drugs during the treatment period

+ In comparison with the first quartile 
Table 6 The association between baseline serum alkaline phosphatase (ALP) and new-onset diabetes, with further adjustment for AST, ALT and GGT

\begin{tabular}{|c|c|c|c|c|c|c|}
\hline \multirow[t]{2}{*}{ ALP, IU/L } & \multirow[t]{2}{*}{$\mathrm{N}$} & \multirow[t]{2}{*}{ No. of events (\%) } & \multicolumn{2}{|l|}{ Crude model } & \multicolumn{2}{|c|}{ Adjusted model* } \\
\hline & & & OR (95\% Cl) & $P$ value $^{\dagger}$ & OR (95\% Cl) & $P$ value $^{\dagger}$ \\
\hline $\begin{array}{l}\text { Continuous, per SD } \\
\text { increment }\end{array}$ & 14,393 & $1549(10.8)$ & $1.07(1.02,1.13)$ & 0.007 & $1.06(1.00,1.13)$ & 0.045 \\
\hline \multicolumn{7}{|l|}{ Quartiles } \\
\hline Q1 (<79) & 3486 & $343(9.8)$ & 1.00 (ref.) & & 1.00 (ref.) & \\
\hline Q2 (79-<96) & 3623 & $381(10.5)$ & $1.08(0.92,1.26)$ & 0.346 & $1.08(0.92,1.28)$ & 0.327 \\
\hline Q3 (96-<116) & 3577 & $390(10.9)$ & $1.12(0.96,1.31)$ & 0.143 & $1.13(0.96,1.33)$ & 0.148 \\
\hline $\mathrm{Q} 4(\geq 116)$ & 3707 & $435(11.7)$ & $1.22(1.05,1.42)$ & 0.010 & $1.23(1.03,1.46)$ & 0.020 \\
\hline$P$ for trend & & & 0.009 & & 0.019 & \\
\hline
\end{tabular}

ALP serum alkaline phosphatase, ALT alanine aminotransferase, AST aspartate aminotransferase, Cl confidence interval, eGFR estimated glomerular filtration rate, GGT gamma glutamyl transpeptidase, $O R$ odds ratio, $S D$ standard deviations, $S B P$ systolic blood pressure

*Adjusted for age, sex, study center, treatment group, body mass index (BMI), smoking, alcohol drinking, family history of diabetes, SBP, fasting glucose (FG), total cholesterol (TC), triglycerides (TG), eGFR, folate, total homocysteine and the use of antihypertensive drugs, AST, ALT, GGT at baseline, as well as time-averaged SBP during the treatment period

+ In comparison with the first quartile

Table 7 The association between change in serum alkaline phosphatase (ALP) and new-onset diabetes

\begin{tabular}{|c|c|c|c|c|c|c|}
\hline \multirow[t]{2}{*}{ ALP, IU/L } & \multirow[t]{2}{*}{$N$} & \multirow[t]{2}{*}{ No. of events (\%) } & \multicolumn{2}{|l|}{ Crude model } & \multicolumn{2}{|c|}{ Adjusted model* } \\
\hline & & & OR $(95 \% \mathrm{CI})$ & $P$ value $^{\ddagger}$ & OR $(95 \% \mathrm{Cl})$ & $P$ value ${ }^{\ddagger}$ \\
\hline Persistently low levels ${ }^{\dagger}$ & 6087 & $549(9.0)$ & 1.00 (ref.) & & 1.00 (ref.) & \\
\hline Decreased levels & 2744 & $237(8.6)$ & $0.95(0.81,1.12)$ & 0.559 & $0.96(0.81,1.14)$ & 0.653 \\
\hline Increased levels & 993 & $162(16.3)$ & $1.97(1.63,2.38)$ & $<0.001$ & $1.97(1.61,2.42)$ & $<0.001$ \\
\hline Persistently high levels & 4511 & $569(12.6)$ & $1.46(1.29,1.65)$ & $<0.001$ & $1.57(1.36,1.81)$ & $<0.001$ \\
\hline
\end{tabular}

ALP serum alkaline phosphatase, $C I$ confidence interval, eGFR estimated glomerular filtration rate, GGT gamma glutamyl transpeptidase, OR odds ratio, SBP systolic blood pressure

*Adjusted for age, sex, study center, treatment group, body mass index (BMI), smoking, alcohol drinking, family history of diabetes, SBP, fasting glucose (FG), total cholesterol (TC), triglycerides (TG), eGFR, folate, total homocysteine and the use of antihypertensive drugs at baseline, as well as time-averaged SBP during the treatment period

+ We categorized the participants into four groups according to median of baseline serum ALP (96 IU/L): persistently low ALP levels (<96 IU/L at both baseline and exit visit), persistently high ALP levels ( $\geq 96 \mathrm{IU} / \mathrm{L}$ at both baseline and exit visit), decreased ALP levels ( $\geq 96 \mathrm{IU} / \mathrm{L}$ at baseline and $<96 \mathrm{IU} / \mathrm{L}$ at exit visit), and increased ALP levels ( $<96 \mathrm{IU} / \mathrm{L}$ at baseline and $\geq 96 \mathrm{IU} / \mathrm{L}$ at exit visit)

‡ In comparison with persistently low ALP levels

rather than ALP isozymes. In fact, a previous casecontrol study had suggested that IAP deficiency was associated with type 2 diabetes mellitus [27]. However, we did not have enough blood sample for the further IAP measurements. Therefore, we could not examine the association between different ALP isozymes and new-onset diabetes. Finally, we have not available data on some diseases associated with increased serum ALP, such as Paget disease, rickets, hyperparathyroidism, osteomalacia, etc.

\section{Conclusions}

In summary, higher serum ALP was significantly associated with increased risk of new-onset diabetes among hypertensive patients, especially in those with lower tHcy or higher FG levels. If further confirmed, our findings support the strategy to identify and modulate diabetes risk in hypertensive patients by measuring and optimizing individual serum ALP levels. 


\begin{tabular}{|c|c|c|c|c|c|}
\hline $\begin{array}{l}\text { Subgroups } \\
\text { Sex }\end{array}$ & $\mathbf{N}$ & Events (\%) & justed OR $(95 \% \mathrm{Cl})^{*}$ & & $\begin{array}{c}\text { P-interaction* } \\
0.492\end{array}$ \\
\hline Male & 5818 & $620(10.7)$ & $1.04(0.94,1.15)$ & $\rightarrow$ & \\
\hline Female & 8575 & $929(10.8)$ & $1.08(1.01,1.16)$ & $\rightarrow$ & \\
\hline Age, year & & & & & 0.059 \\
\hline$<60$ & 7250 & $745(10.3)$ & $1.14(1.05,1.24)$ & $=$ & \\
\hline$\geq 60$ & 7143 & $804(11.3)$ & $1.03(0.95,1.11)$ & 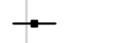 & \\
\hline $\mathrm{BMI}, \mathrm{kg} / \mathrm{m}^{2}$ & & & & & 0.588 \\
\hline$<24$ & 5976 & $494(8.3)$ & $1.04(0.95,1.15)$ & - & \\
\hline$\geq 24$ & 8413 & $1054(12.5)$ & $1.08(1.00,1.16)$ & $\rightarrow$ & \\
\hline Treatment group & & & & & 0.916 \\
\hline Enalapril & 7215 & $759(10.5)$ & $1.07(0.99,1.17)$ & $=$ & \\
\hline Enalapril-folic acid & 7178 & $790(11.0)$ & $1.07(0.99,1.16)$ & $\rightarrow$ & \\
\hline Current smoking & & & & & 0.230 \\
\hline No & 11018 & $1185(10.8)$ & $1.09(1.02,1.16)$ & $\rightarrow$ & \\
\hline Yes & 3375 & $364(10.8)$ & $1.00(0.88,1.14)$ & $\cdot-$ & \\
\hline Current Alcohol drinking & & & & & 0.941 \\
\hline No & 10952 & $1194(10.9)$ & $1.07(1.00,1.14)$ & $=$ & \\
\hline Yes & 3437 & $355(10.3)$ & $1.07(0.93,1.22)$ & $=$ & \\
\hline SBP at baseline, $\mathrm{mmHg}$ & & & & & 0.557 \\
\hline$<160$ & 5399 & $558(10.3)$ & $1.05(0.95,1.15)$ & 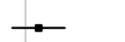 & \\
\hline$\geq 160$ & 8994 & $991(11.0)$ & $1.08(1.01,1.16)$ & $\rightarrow$ & \\
\hline Time-averaged SBP, $\mathrm{mmHg}$ & & & & & 0.911 \\
\hline$<140$ & 8438 & $771(9.1)$ & $1.07(0.99,1.16)$ & $=$ & \\
\hline$\geq 140$ & 5955 & $778(13.1)$ & $1.07(0.98,1.16)$ & $\rightarrow$ & \\
\hline Total homocysteine, $\mu \mathrm{mol} / \mathrm{L}$ & & & & & 0.007 \\
\hline$<10$ & 2849 & $296(10.4)$ & $1.24(1.10,1.40)$ & $\rightarrow$ & \\
\hline$\geq 10$ & 11537 & $1253(10.9)$ & $1.03(0.96,1.10)$ & $\rightarrow$ & \\
\hline Total cholesterol, $\mathrm{mmol} / \mathrm{L}$ & & & & & 0.529 \\
\hline$<5.2$ & 6047 & $642(10.6)$ & $1.09(1.00,1.19)$ & 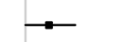 & \\
\hline$\geq 5.2$ & 8345 & $907(10.9)$ & $1.05(0.97,1.14)$ & $\rightarrow$ & \\
\hline Fasting glucose, $\mathrm{mmol} / \mathrm{L}$ & & & & & 0.009 \\
\hline$<5.9$ (quartile 3 ) & 10766 & $763(7.1)$ & $1.00(0.93,1.08)$ & $\rightarrow$ & \\
\hline$\geq 5.9$ & 3627 & $786(21.7)$ & $1.16(1.07,1.27)$ & $\rightarrow$ & \\
\hline $\begin{array}{l}\text { CCB usage during the treatment period } \\
\mathrm{No}\end{array}$ & 2567 & & $107(0.93123)$ & $\rightarrow$ & 0.971 \\
\hline Yes & 11826 & $1303(11.0)$ & $1.07(1.00,1.14)$ & 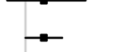 & \\
\hline Diuretics usage during the treatment period & & & & & 0.590 \\
\hline No & 6703 & $676(10.1)$ & $1.09(1.00,1.18)$ & $=$ & \\
\hline Yes & 7690 & $873(11.4)$ & $1.06(0.97,1.14)$ & $\rightarrow$ & \\
\hline & & & & 1.3 & \\
\hline
\end{tabular}

Fig. 5 The association between baseline serum alkaline phosphatase (ALP, per SD increment) and new-onset diabetes in various groups. Adjusted for age, sex, study center, treatment group, body mass index (BMI), smoking, alcohol drinking, family history of diabetes, SBP, fasting glucose (FG), total cholesterol (TC), triglycerides (TG), eGFR, folate, total homocysteine and the use of antihypertensive drugs at baseline, as well as time-averaged SBP during the treatment period, if not be stratified

\section{Abbreviations}

ALP: Alkaline phosphatase; BMl: Body mass index; BP: Blood pressure; CCB: Calcium channel blockers; CVD: Cardiovascular disease; CSPPT: China Stroke Primary Prevention Trial; DBP: Diastolic blood pressure; eGFR: Estimated glomerular filtration rate; FG: Fasting glucose; HDL-C: High-density lipoprotein; IFG: Impaired fasting glucose; SBP: Systolic blood pressure.

\section{Acknowledgements}

We are grateful to the investigators and participants of the CSPPT, the parent study, who made this report possible.
Authors' contributions

YYZ, XPX and XHQ conceived and designed the study. YYZ, XHQ and CZ contributed to statistical analysis. YYZ and XHQ drafted the manuscript. All authors contributed to collect data and reviewed/edited the manuscript important intellectual content. All authors read and approved the final manuscript.

Funding

The study was supported by funding from the following: the National Key Research and Development Program [2016YFE0205400, 2018ZX09739010, 2018ZX09301034003]; the Science and Technology Program of Guangdong 
[2020B121202010]; the Science and Technology Planning Project of Guangzhou [201707020010]; the Science, Technology and Innovation Committee of Shenzhen [GJHS20170314114526143, JSGG20180703155802047]; the Economic, Trade and Information Commission of Shenzhen Municipality [20170505161556110, 20170505160926390, 201705051617070], the National Natural Science Foundation of China [81730019, 81973133] and Outstanding Youths Development Scheme of Nanfang Hospital, Southern Medical University [2017J009].

\section{Availability of data and materials}

The data and study materials that support the findings of this study will be available from the corresponding authors (pharmaqin@126.com) upon request, after the request is submitted and formally reviewed and approved by the Ethics Committee of the Institute of Biomedicine, Anhui Medical University.

\section{Ethics approval and consent to participate}

The parent study (the CSPPT) and the current study were approved by the Ethics Committee of the Institute of Biomedicine, Anhui Medical University, Hefei, China (Federalwide Assurance Number 00001263). All participants provided written informed consent.

\section{Consent for publication}

Not applicable.

\section{Competing interests}

XPX reports grants from the National Key Research and Development Program [2016YFE0205400, 2018ZX09739010, 2018ZX09301034003]; the Science and Technology Program of Guangdong [2020B121202010]; the Science and Technology Planning Project of Guangzhou [201707020010]; the Science, Technology and Innovation Committee of Shenzhen [GJHS20170314114526143, JSGG20180703155802047]; the Economic, Trade and Information Commission of Shenzhen Municipality [20170505161556110, 20170505160926390 , 201705051617070].XHQ reports grants from the National Natural Science Foundation of China [81730019, 81973133] and Outstanding Youths Development Scheme of Nanfang Hospital, Southern Medical University [2017J009].No other disclosures were reported.

\section{Author details}

${ }^{1}$ Division of Nephrology, Nanfang Hospital, Southern Medical UniversityNational Clinical Research Center for Kidney DiseaseState Key Laboratory of Organ Failure ResearchGuangdong Provincial Institute of Nephrology, Guangdong Provincial Key Laboratory of Renal Failure Research, Guangzhou Regenerative Medicine and Health Guangdong Laboratory, Guangzhou 510515, China. ${ }^{2}$ Department of Cardiology, Peking University First Hospital, Beijing 100034, China. ${ }^{3}$ Institute of Biomedicine, Anhui Medical University, Hefei 230032, China. ${ }^{4}$ Beijing Advanced Innovation Center for Food Nutrition and Human Health, College of Food Science and Nutritional Engineering, China Agricultural University, Beijing 100083, China. ${ }^{5}$ Department of Population, Family and Reproductive Health, Johns Hopkins University Bloomberg School of Public Health, 615 N. Wolfe Street, E4132, Baltimore, MD 21205-2179, USA.

Received: 24 August 2020 Accepted: 17 October 2020

Published online: 24 October 2020

\section{References}

1. Saeedi P, Petersohn I, Salpea P, Malanda B, Karuranga S, Unwin N, et al. Global and regional diabetes prevalence estimates for 2019 and projections for 2030 and 2045: results from the International Diabetes Federation Diabetes Atlas, 9th edition. Diabetes Res Clin Pract. 2019;157:107843.

2. Qin X, Li J, Zhang Y, Ma W, Fan F, Wang B, et al. Prevalence and associated factors of diabetes and impaired fasting glucose in Chinese hypertensive adults aged 45 to 75 years. PLoS ONE. 2012;7(8):e42538.

3. Petrie JR, GuzikTJ, Touyz RM. Diabetes, hypertension, and cardiovascular disease: clinical insights and vascular mechanisms. Can J Cardiol. 2018;34(5):575-84.
4. Rao Kondapally Seshasai S, Kaptoge S, Thompson A, Di Angelantonio E, Gao P, Sarwar N, et al. Diabetes mellitus, fasting glucose, and risk of causespecific death. N Engl J Med. 2011;364(9):829-41.

5. Ballestri S, Zona S, Targher G, Romagnoli D, Baldelli E, Nascimbeni F, et al. Nonalcoholic fatty liver disease is associated with an almost twofold increased risk of incident type 2 diabetes and metabolic syndrome. Evidence from a systematic review and meta-analysis. J Gastroenterol Hepatol. 2016;31(5):936-44.

6. Kunutsor SK, Apekey TA, Walley J. Liver aminotransferases and risk of incident type 2 diabetes: a systematic review and meta-analysis. Am J Epidemiol. 2013;178(2):159-71.

7. Harmey D, Hessle L, Narisawa S, Johnson KA, Terkeltaub R, Millan JL. Concerted regulation of inorganic pyrophosphate and osteopontin by akp2, enpp1, and ank: an integrated model of the pathogenesis of mineralization disorders. Am J Pathol. 2004;164(4):1 199-209.

8. Nunes JP, Melão F, Godinho AR, Rodrigues JD, Maciel MJ. Plasma alkaline phosphatase and survival in diabetic patients with acute myocardial infarction. Ann Transl Med. 2016:4(11):210.

9. Kim DW, Hwang SY, Nam YJ, Kim D, Shin SJ, Yoon HE. The combined prognostic significance of alkaline phosphatase and vascular calcification in patients with end-stage kidney disease. Nutr Metab Cardiovasc Dis. 2020;30(9):1476-83.

10. Zwakenberg SR, van der Schouw YT, Schalkwijk CG, Spijkerman AMW, Beulens JWJ. Bone markers and cardiovascular risk in type 2 diabetes patients. Cardiovasc Diabetol. 2018;17(1):45.

11. Nannipieri M, Gonzales C, Baldi S, Posadas R, Williams K, Haffner SM, et al. Liver enzymes, the metabolic syndrome, and incident diabetes: the Mexico City diabetes study. Diabetes Care. 2005;28(7):1757-62.

12. Nakanishi N, Suzuki K, Tatara K. Serum gamma-glutamyltransferase and risk of metabolic syndrome and type 2 diabetes in middle-aged Japanese men. Diabetes Care. 2004:27(6):1427-32.

13. Hanley AJ, Williams K, Festa A, Wagenknecht LE, D'Agostino RJ, Kempf J, et al. Elevations in markers of liver injury and risk of type 2 diabetes: the insulin resistance atherosclerosis study. Diabetes. 2004;53(10):2623-32.

14. Chen SC, Tsai SP, Jhao JY, Jiang WK, Tsao CK, Chang LY. Liver fat, hepatic enzymes, alkaline phosphatase and the risk of incident type 2 diabetes: a prospective study of 132,377 adults. Sci Rep. 2017;7(1):4649.

15. Qin X, Huo Y. H-Type hypertension, stroke and diabetes in China: opportunities for primary prevention. J Diabetes. 2016;8(1):38-40.

16. Zhang Y, Nie J, Zhang Y, Li J, Liang M, Wang G, et al. Degree of blood pressure control and incident diabetes mellitus in Chinese adults with hypertension. J Am Heart Assoc. 2020;9(16):e017015.

17. Huo Y, Li J, Qin X, Huang Y, Wang X, Gottesman RF, et al. Efficacy of folic acid therapy in primary prevention of stroke among adults with hypertension in China: the CSPPT randomized clinical trial. JAMA. 2015;313(13):1325-35

18. Zhang Y, He P, Li Y, Zhang Y, Li J, Liang M, et al. Positive association between baseline brachial-ankle pulse wave velocity and the risk of new-onset diabetes in hypertensive patients. Cardiovasc Diabetol. 2019;18(1):111.

19. Qin X, Li J, Zhang Y, Chen D, Wang B, He M, et al. Effect of folic acid supplementation on risk of new-onset diabetes in adults with hypertension in China: findings from the China Stroke Primary Prevention Trial (CSPPT). J Diabetes. 2016;8(2):286-94.

20. Qin $X$, Li Y, He M, Tang G, Yin D, Liang M, et al. Folic acid therapy reduces serum uric acid in hypertensive patients: a substudy of the China Stroke Primary Prevention Trial (CSPPT). Am J Clin Nutr. 2017;105(4):882-9.

21. Zhou C, Liu M, Zhang Z, Zhang Y, Nie J, Liang M, et al. Positive association of serum uric acid with new-onset diabetes in Chinese women with hypertension in a retrospective analysis of the China Stroke Primary Prevention Trial. Diabetes Obes Metab. 2020;22(9):1598-606.

22. Zhang Y, Li H, Lin T, Guo H, Jiang C, Xie L, et al. Plasma selenium levels and risk of new-onset diabetes in hypertensive adults. J Trace Elem Med Biol. 2019;56:6-12.

23. Levey AS, Stevens LA, Schmid CH, Zhang YL, Castro AF 3rd, Feldman HI, et al. A new equation to estimate glomerular filtration rate. Ann Intern Med. 2009;150(9):604-12.

24. Chinese Diabetes Society. China guideline for type 2 diabetes (2007). Zhonghua Yi Xue Za Zhi. 2008:88:1227-45. 
25. Chinese Diabetes Society. China guideline for type 2 diabetes (2010). Chin J of Diabetes. 2012:20:S1-36.

26. Sharma U, Pal D, Prasad R. Alkaline phosphatase: an overview. Indian J Clin Biochem. 2014;29(3):269-78.

27. Malo MS. A high level of intestinal alkaline phosphatase is protective against type 2 diabetes mellitus irrespective of obesity. EBioMedicine. 2015;2(12):2016-23.

28. De Silva N, Borges MC, Hingorani AD, Engmann J, Shah T, Zhang X, et al. Liver function and risk of type 2 diabetes: bidirectional mendelian randomization study. Diabetes. 2019;68(8):1681-91.

29. Liu J, Au YS, Lin SL, Leung GM, Schooling CM. Liver enzymes and risk of ischemic heart disease and type 2 diabetes mellitus: a mendelian randomization study. Sci Rep. 2016;6:38813.

30. Azpiazu D, Gonzalo S, Villa-Bellosta R. Tissue non-specific alkaline phosphatase and vascular calcification: a potential therapeutic target. Curr Cardiol Rev. 2019;15(2):91-5.

31. Fadini GP, Pauletto P, Avogaro A, Rattazzi M. The good and the bad in the link between insulin resistance and vascular calcification. Atherosclerosis. 2007;193(2):241-424.

32. Bouvet C, Peeters W, Moreau S, DeBlois D, Moreau P. A new rat model of diabetic macrovascular complication. Cardiovasc Res. 2007;73(3):504-11.

33. House LM 2nd, Morris RT, Barnes TM, Lantier L, Cyphert TJ, McGuinness $\mathrm{OP}$, et al. Tissue inflammation and nitric oxide-mediated alterations in cardiovascular function are major determinants of endotoxin-induced insulin resistance. Cardiovasc Diabetol. 2015;14:56.

34. Schultz-Hector S, Balz K, Bohm M, Ikehara Y, Rieke L. Cellular localization of endothelial alkaline phosphatase reaction product and enzyme protein in the myocardium. J Histochem Cytochem. 1993;41(12):1813-21.

35. Boo YC, Jo H. Flow-dependent regulation of endothelial nitric oxide synthase: role of protein kinases. Am J Physiol Cell Physiol. 2003;285(3):C499-508.

36. Damera S, Raphael KL, Baird BC, Cheung AK, Greene T, Beddhu S. Serum alkaline phosphatase levels associate with elevated serum C-reactive protein in chronic kidney disease. Kidney Int. 2011;79(2):228-33.

37. Cheung BM, Ong KL, Cheung RV, Wong LY, Wat NM, Tam S, et al. Association between plasma alkaline phosphatase and C-reactive protein in Hong Kong Chinese. Clin Chem Lab Med. 2008;46(4):523-7.

38. Sara JD, Taher R, Kolluri N, Vella A, Lerman LO, Lerman A. Coronary microvascular dysfunction is associated with poor glycemic control amongst female diabetics with chest pain and non-obstructive coronary artery disease. Cardiovasc Diabetol. 2019;18(1):22.

39. Huemer MT, Huth C, Schederecker F, Klug SJ, Meisinger C, Koenig W, et al. Association of endothelial dysfunction with incident prediabetes, type 2 diabetes and related traits: the KORA F4/FF4 study. BMJ Open Diabetes Res Care. 2020;8(1):e001321.

40. Pradhan AD, Manson JE, Rifai N, Buring JE, Ridker PM. C-reactive protein, interleukin 6, and risk of developing type 2 diabetes mellitus. JAMA. 2001;286(3):327-34

41. Bao X, Borné Y, Johnson L, Muhammad IF, Persson M, Niu K, et al. Comparing the inflammatory profiles for incidence of diabetes mellitus and cardiovascular diseases: a prospective study exploring the "common soil" hypothesis. Cardiovasc Diabetol. 2018;17(1):87.

42. Faerch K, Vaag A, Holst JJ, Glümer C, Pedersen O, Borch-Johnsen K. Impaired fasting glycaemia vs impaired glucose tolerance: similar impairment of pancreatic alpha and beta cell function but differential roles of incretin hormones and insulin action. Diabetologia. 2008;51(5):853-61.

43. Ha J, Sherman A. Type 2 diabetes: one disease, many pathways. Am J Physiol Endocrinol Metab. 2020;319(2):E410-26.

44. Beulens J, Rutters F, Rydén L, Schnell O, Mellbin L, Hart HE, et al. Risk and management of pre-diabetes. Eur J Prev Cardiol. 2019;26(2 suppl):47-54.

45. Fang K, Chen Z, Liu M, Peng J, Wu P. Apoptosis and calcification of vascular endothelial cell under hyperhomocysteinemia. Med Oncol. 2015:32(1):403.

46. Spence JD, Yi Q, Hankey GJ. B vitamins in stroke prevention: time to reconsider. Lancet Neurol. 2017;16(9):750-60.

47. Zhao M, Wu G, Li Y, Wang X, Hou FF, Xu X, et al. Meta-analysis of folic acid efficacy trials in stroke prevention: Insight into effect modifiers. Neurology. 2017;88(19):1830-8.

48. Stranges S, Marshall JR, Natarajan R, Donahue RP, Trevisan M, Combs GF, et al. Effects of long-term selenium supplementation on the incidence of type 2 diabetes: a randomized trial. Ann Intern Med. 2007;147(4):217-23.

49. Bleys J, Navas-Acien A, Guallar E. Serum selenium and diabetes in U.S. adults. Diabetes Care. 2007;30(4):829-34.

\section{Publisher's Note}

Springer Nature remains neutral with regard to jurisdictional claims in published maps and institutional affiliations.
Ready to submit your research? Choose BMC and benefit from:

- fast, convenient online submission

- thorough peer review by experienced researchers in your field

- rapid publication on acceptance

- support for research data, including large and complex data types

- gold Open Access which fosters wider collaboration and increased citations

- maximum visibility for your research: over 100M website views per year

At BMC, research is always in progress.

Learn more biomedcentral.com/submissions 